FINANCIEEL BELEID - ONDERNEMINGSFINANCIERING - DERIVATEN

\title{
Financiële innovaties en ondernemingsbeleid
}

Prof. Dr. A.W.A. Boot en Drs. P.J.W. Duffhues

\section{Inleiding}

De financiële wereld heeft haar grip op ons allen in de laatste decennia steeds meer versterkt. Geen nieuwsuitzending gaat voorbij zonder melding van de laatste koersniveaus van de beurzen in Londen, New York, Parijs of Amsterdam. De 'markt' is het economische ordeningsmechanisme van de jaren negentig. Van de oprichting van effectenbeurzen in de voormalige dirigistische communistische wereld, de gemeenschappelijke Europese markt en haar financiële evenknie de Europese Monetaire Unie (EMU), tot 'marktwerking' in alle facetten van het overheidsbeleid.

Het marktbeginsel, en de algemene aanvaarding daarvan, heeft in niet geringe mate bijgedragen aan de alsmaar toenemende stroom van financiële innovaties. De veelheid aan financiële producten maken het voor ondernemingen en beleggers beter dan voorheen mogelijk om risico's af te wentelen of juist op te zoeken. Ronduit spectaculair zijn de ontwikkelingen op het gebied van derivaten of afgeleide financiële instrumenten. Naast de inmiddels traditionele opties op aandelen, bestaan er (althans in de Amerikaanse markt) inmiddels ook 'catastrophe'-opties en kredietrisico-opties. De 'catastrophe'-opties bieden een verzekering tegen bepaalde rampzalige natuurverschijnselen, de kredietrisico-opties richten zich -

Prof. Dr. A.W.A. Boot is hoogleraar Ondernemingsfinanciering en Financiële Markten aan de Universiteit van Amsterdam.

Drs. P.J.W. Duffhues is universitair hoofddocent Ondernemingsfinanciering aan de Katholieke Universiteit Brabant te Tilburg. zoals de naam al zegt - op kredietrisico. Hoewel bijzonder en nieuw zijn deze instrumenten qua structuur identiek aan de relatief eenvoudige standaardopties en futures; het 'nieuwe' schuilt dan ook in het type risico (krediet- respectievelijk catastrophe-risico) waar ze zich op richten en in de omvang van de markt die kredietderivaten kunnen bereiken. De markt wordt echter ook overspoeld met allerlei zeer complexe en samengestelde financiële instrumenten; het begrip exotische opties is in dit verband voldoende indicatief (Bongartz-Renaud, 1993).

Hoewel de proliferatie van derivaten het meest in het oog springt, betreft de financiële innovatiegolf evenzeer niet-afgeleide financiële instrumenten. Hierbij zijn mel name van belang samengestelde financieringsvormen. Dit betreffen hasisfinancieringsvormen zoals aandelen en obligaties die gecombineerd kunnen worden met afgeleide financiële instrumenten. Een voorbeeld is een converteerbare obligatielening die een lening combineert met het recht (optie!) tot conversie in aandelen. Deze combinaties - ook wel 'structured deals' genoemd - bieden nagenoeg oneindige mogelijkheden voor financiële innovaties. In Tabel 1 zijn de verschillende groepen van financiële instrumenten weergegeven.

Dit themanummer van het MAB gaat over het ontwerp en het gebruik van financiële instrumenten. Een vraag die daarbij centraal staat is wat de toegevoegde waarde van deze aanhoudende stroom van financiële innovaties is. Voor buitenstaanders maar zelfs ook voor insiders - de participanten op de financiële markten - blijft de financiële innovatiegolf een raadsel. Het is überhaupt een raadsel, wat er goed is aan al die 
Tabel 1: Groepen van financiële instrumenten

I Basisfinancieringsvormen

die op de balans worden vermeld ('on balance sheet' financiële instrumenten); voorbeelden zijn aandelenkapitaal, obligatielening.

2 Afgeleide financiële instrumenten (derivaten) die 'off the balance sheet' worden geregistreerd; voorbeelden zijn forwards. futures, opties en swaps. 3 Samengestelde financieringsvormen ('structured deals')

ofwel vermogensoverdrachten met aangehechte of impliciete derivaten die deels 'on the balance' en deels 'off the balance sheet' worden vastgelegd: 'hybrids', 'embeddo's' of ook wel 'structured deals' genoemd (bijvoorbeeld een lening met recht tot vervroegde aflossing of een converteerbare obligatielening).

activiteit op financiële markten. Het verhandelen van 'papiertjes' (aandelen, opties of andere financiële instrumenten) lijkt niet bij te dragen aan onze collectieve welvaart. Alle activiteit lijkt louter gedreven door winstbejag: het vandaag kopen van een aandeel of optie en het morgen (of op een ander moment) verkopen tegen hopelijk een hogere prijs. Deze karakterisering van de financiële markten suggereert dat het verhandelen van financiële instrumenten sommigen zal verrijken ten koste van anderen, maar dat wij met z'n allen tezamen er niet beter van worden: er wordt immers niets gecreëerd, althans geen min of meer tastbare goederen in de gebruikelijke economische zin.

Het antwoord uit de economische theorie is dat financiële markten onontbeerlijk zijn voor een efficiënte allocatie van financiële middelen. Hiermee wordt ruwweg bedoeld dat markten er voor zorgen dat financiële middelen op die plaats terecht komen waar het optimaal is om ze te gebruiken. Hoewel hierbij de nadruk ligt op de allocatie van financiële middelen, is er juist ook sprake van het alloceren van risico's. Wanneer een onderneming aandelen of andere vermogenstitels uitgeeft worden niet alleen financiële middelen aangetrokken maar wordt tegelijkertijd in een bepaalde mate ondernemingsrisico afgewenteld op beleggers in de markt. In het geval van afgeleide financiële instrumenten (derivaten) staat het heralloceren van risico's nog meer centraal. Met derivaten worden immers geen financiële middelen door ondernemingen aangetrokken. Niet voor niets worden derivaten ook wel (afgeleide) financiële instrumenten genoemd. Een nadere typering wordt gegeven in kader 1 (pag. 338). Maar wat is de waarde van deze risicoallocerende instrumenten? In dit themanummer wordt een aantal pogingen ondernomen om deze vraag te beantwoorden.

In de bijdrage van Van de Ven wordt gepleit voor de introductie van een hypotheek-future (of andere derivaten op prijsindices van huizen) omdat deze de financiering van ons woningbezit zou kunnen vergemakkelijken. Duffhues bekijkt de toegevoegde waarde van het ESCAPE-product, een recente innovatie op de Nederlandse markt. In zijn analyse van de drijvende krachten achter de financiële innovatiegolf benadrukt Duffhues de specifieke voordelen van financiële innovaties voor beleggers. De bijdrage van Smid en Tempelaar is complementair aan die van Duffhues. Zij analyseren een andere recente innovatie, de 'click'-fondsen, die als beleggingsproduct zeer populair zijn geworden bij een groot publiek. Evenals in de bijdrage van Duffhues staat bij Smid en Tempelaar de invalshoek van de belegger centraal. In deze inleidende bijdrage wijken wij hiervan af en kiezen als uitgangspunt de onderneming. Wij vragen ons af wat het belang is van financiële innovaties voor het ondernemingsbeleid. Wij kiezen dus nadrukkelijk niet het perspectief van de belegger. Van een echte tegenstelling met de bijdragen van Duffhues en Smid en Tempelaar is echter geen sprake: wat goed is voor beleggers zal meestal de werking van financiële markten, en daarmee de toegankelijkheid ervan voor ondernemingen vergroten. Het themanummer wordt afgesloten met enige ervaringen uit de praktijk. Een korte bijdrage van Klaassen en De Man inventariseert het gebruik van derivaten door Nederlandse ondernemingen. Ten slotte bekijkt Van Schoten de gewenste en feitelijk geconstateerde beheersingsmaatregelen voor een (verantwoord) gebruik van afgeleide financiële instrumenten binnen ondernemingen.

Dit themanummer biedt daarmee een betrekkelijk volledig overzicht van de problematiek van financiële instrumenten: van toegevoegde waarde voor ondernemingen en beleggers tot gewenste beheersingsmaatregelen. In deze inleidende bijdrage bekijken we - zoals gezegd - het belang 
van financiële innovaties voor het ondernemingsbeleid. Allereerst is het de vraag of het financiële beleid - en dus ook risicomanagement en hedging

- überhaupt van belang is.

\section{Kader 1: Een nadere typering van financiële instrumenten}

Financiële instrumenten worden in deze beschouwing in ruime zin gedefinieerd als vermogenstitels die betrekking hebben op de overdracht van risico; in een aantal gevallen hebben financiële instrumenten ook overdracht van vermogen (financiële middelen) tot gevolg. Vermogensoverdracht is dus in deze definitie niet kenmerkend voor een financieel instrument.

Overdracht van risico vindt bijvoorbeeld plaats als een conventionele financieringstransactie tot stand komt. Dat is de eerste en meest bekende groep van financiële instrumenten. Afspraken over het door beide partijen te lopen risico gaan hier samen met een vermogensoverdracht. Wanneer bijvoorbeeld aandelen worden geëmitteerd, brengt de emitterende onderneming vermogenstitels in omloop waarvan de houders het residuele (in het algemeen veruit het grootste) ondernemingsrisico dragen. Was voor een gewone obligatielening gekozen dan was die overdracht van ondernemingsrisico veel beperkter geweest (helemaal uitsluiten is nauwelijks mogelijk). Er was in dat geval meer risico in de onderneming achtergebleven waarvoor nog andere verschaffers van vermogen (bijvoorbeeld van achtergesteld vreemd vermogen of van eigen vermogen) zouden moeten worden gevonden. Daar staat een lagere vergoeding voor de verschaffer van obligatievermogen tegenover. De overdracht van risico heefi bij deze eerste groep van financiële instrumenten altijd een pendant namelijk een gelijktijdige vermogensoverdracht voor bepaalde of onbepaalde tijd. We noemen deze financiële instrumenten basisfinancieringsvormen.

Overdracht van risico kan ook betrekking hebben op het risico 'sec' zonder dat er een vermogensoverdracht plaatsvindt. Daarmee hebben we de tweede groep (zie tabel 1) van financiële instrumenten bereikt: de afgeleide financiële instrumenten (derivaten). Derivaten zijn afgeleide producten waarvan de waarde voor een belangrijk deel wordt bepaald door de waarde van een andere ('onderliggende') waarde. Het zijn separaat gelanceerde instrumenten met als doel, bijvoorbeeld, het afdekken van risico's. We denken dan bijvoorbeeld aan het verkopen van een valutarisico of een renterisico door de onderneming; dit is mogelijk met behulp van een financieel instrument in enge zin zoals een valutatermijncontract of een rente-swap. Zeer recent zijn in de VS ook putopties op geldleningen geïntroduceerd met het doel het kredietwaardigheidsrisico op leningen verhandelbaar te maken. Op het moment van de transactie vindt bij een derivaat geen vermogensoverdracht in de vorm van een hoofdsom plaats; wel wordt er soms iets betaald maar dat is het relatief geringe bedrag dat betrekking heeft op de prijs van het risico zelf (bijvoorbeeld de te betalen optiepremie als 'upfront fee'). Mits goed gebruikt. kunnen deze derivaten bijzonder waardevol zijn en de continuïteit van de onderneming zeer dienen. Is aan deze eis niet voldaan, dan kunnen zij regelrecht leiden tot een financiële ramp en discontinuïteit.

De derde groep van financiële instrumenten beval instrumenten waarvoor geldt dat daarin de eigenschappen van de twee eerste groepen worden gecombineerd; (zie wederom tabel 1). Er is zowel sprake van een vermogensoverdracht (met de daaraan op zichzelf reeds inherente risico-overdracht) als van een additionele overdracht van risico 'sec'. Dit laatste blijkt uit de bijzondere rechten en plichten die aan de transactie kleven wanneer deze wordt vergeleken met een klassieke transactie. Deze rechten en plichten hebben eveneens het karakter van derivaten. In dit geval zijn het echter geen separaat geëmitteerde derivaten maar verpakte, aangehechte, impliciete derivaten. Dergelijke financieringstransacties zijn bekend als vermogensoverdrachttransacties met "toeters en bellen": 'structured deals' of hybride financieringsvormen. Een blik op de aard van deze toeters en bellen geeft alras het inzicht dat het hier gaat om instrumenten van het niet-conventionele type. Een voorbeeld is een aandelenemissie waarbij de inschrijvers behalve het gewone aandeel zelf ook een aandelen-callwarrant van de onderneming kopen; er zit nu een door de onderneming geschreven call optie ingebakken in een standaardaandelenuitgifte.

Van de groepen 2 en 3 kan worden gezegd dat deze één of meer voorwaardelijke aanspra(a)k(en) bevat(ten).

Deze contingente claims kunnen in de toekomst tot betaling en/of ontvangst van aanzienlijke bedragen leiden afhankelijk van het verloop van één of andere afgesproken variabele. bijvoorbeeld de geldmarktrente (zie Duffhues (1994) voor meer details).

Standaardopvatting is dat conventionele typen van financiële instrumenten 'onschuldige wezens' zijn maar dat alle kwaad van de (financiële) wereld schuilt in groep 2. Overigens is men bij dat verwijt doorgaans nogal selectief omdat bijvoorbeeld recente financiële schandalen soms ook te maken hadden met 'simpele' basisfinancieringsvormen, zoals obligaties. 


\section{Irrelevantie van het financiële ondernemingsbeleid?}

Een belangrijk resultaat in de theorie van de financiering stelt dat beleggers - de houders van de aandelen en obligaties van een ondernemingnaar gelang hun individuele preferenties zelf risico's kunnen diversifiëren en zo nodig hedgen, en dat het daarom onnodig is dit op ondernemingsniveau te doen. Dit resultaat is een uitvloeisel van de binnen de financieringstheorie welbekende Modigliani en Miller-proposities. Deze Nobelprijswinnaars in de economie hebben aangetoond dat in een ideale wereld zonder fricties of andere verstoringen de financiële beslissingen van de onderneming - waaronder de keuze van vermogensvormen, hedging en dividendpolitiek irrelevant zijn. In deze wereld zijn alleen de reële beslissingen, zoals het wel of niet tot ontwikkeling brengen van een nieuw product, van belang. Een fraai voorbeeld hiervan is de tamelijk provocerende uitspraak van Dufey en Srinivasulu uit 1983: 'Foreign exchange risk does not exist; even if it exists, it needs not be hedged; even if it is to be hedged, corporations need not hedge it'.
Deze zienswijze suggereert een volledige ontkoppeling van beslissingen in de reële sfeer van die in de financiële sfeer. De suggestie is dat de reële economie - omvattende de productie van het totaal aan goederen en diensten - voorziet in de welvaart zonder noemenswaardige bijdrage van de financiële wereld. De potentiële waardecreatie van investeringsbeslissingen kan dan geheel worden los gezien van het financiële beleid. In tabel 2 is dit weergegeven als 'niveau 1 '.

De strikte scheiding van reële en financiële beslissingen is in sterke mate afhankelijk van de door Modigliani en Miller veronderstelde 'perfecte' markten. Onder deze aanname is er sprake van geen enkele frictie. Dit betekent onder meer dat er geen informatieverschillen bestaan tussen onderneming en financiële markt. De markt weet alles, en ook het besluitvormingsproces van de onderneming is voor de markt volledig voorspelbaar. Het is niet echt verrassend dat de onderneming bij een dergelijke transparantie en volledige eenduidigheid te allen tijde tegen de 'juiste' kostenvoet financiële middelen kan aantrekken. Onder dergelijke omstandigheden weten (externe)

Tabel 2: De relatie tussen de financiële sfeer en de reële sfeer in de economie: geïdealiseerd en onder invloed van storingsfactoren

Niveau 1

Beslissingen in de reële sfeer (schepping van netto contante waarde)

separaat

Niveau 2

Onderinvestering

afhankelijk

\section{Beslissingen in de}

financiële sfeer:

1 vermogensverhoudingen

2 dividendbeleid

3 risicomanagement (hedging)

Imperfecties:

- Faillissementskosten

- Informatieverschillen

- Transactiekosten

- Fiscale overwegingen

Overinvestering

Derving van netto

contante waarde 
financiers precies waar ze aan toe zijn, en de onderneming wordt geacht waardemaximaliserende beslissingen te nemen, die gezien de transparantie volledig afdwingbaar zijn. Kortom, de reële beslissingen zijn optimaal en het financiële beleid is bijzaak.

Het spreekt voor zich dat wij niet in zo'n ideale wereld leven. Immers in werkelijkheid zijn er allerlei fricties. Zo is er veelal geen sprake van volledige transparantie, en behoren informatieverschillen tot de orde van de dag. Bovendien zijn er allerlei andere fricties, zoals transactiekosten, faillissementskosten en belastingen. Juist deze fricties maken het financiële beleid relevant. Een fiscaalvriendelijke behandeling van vreemd vermogen kan bijvoorbeeld leiden tot een voorkeur voor meer vreemd vermogen in de vermogensstructuur; mogelijke faillissementskosten hebben daarentegen een tegengesteld effect.

Informatieverschillen en gebrek aan transparantie kunnen het aantrekken van externe financiering bemoeilijken, en daarmee het investeringsbeleid beïnvloeden; mogelijke onderinvesteringen zijn het gevolg. Zie daar de interacties tussen reële beslissingen (investeringen) en het financiële beleid bij het bestaan van fricties. Tegelijkertijd kan een gebrek aan transparantie managers vrijwaren van het afleggen van verantwoording. Met de scheiding tussen management en financiers zou het management de belangen van de financiers uit het oog kunnen verliezen. De vraag is hoe kan worden voorkomen dat managers 'empire builders' worden en intern beschikbare liquide middelen hoe dan ook gaan investeren. Overinvesteringen behoren dus evenzeer tot de mogelijkheden.

De onderlinge afhankelijkheid van het reële en financiële beleid komt tot uitdrukking in tabel 2 als 'niveau 2 '. Hierin wordt de investeringsactiviteit (mede) afhankelijk gesteld van de beslissingen in de financiële sfeer. De oorzaak van deze afhankelijkheid is de verzameling van imperfecties waarmee in de werkelijkheid door beleggers (financiers) en management van bedrijven moet worden omgegaan.' Met het gerijpte inzicht van een mogelijke afhankelijkheid staat vast dat de theorie veel praktischer en meer op bestudering van instituties gericht moet worden dan in de 'perfecte' Modigliani en Miller-wereld besloten ligt. Het gaat bij de drie vormen van financiële beslissingen (rechts bovenin tabel 2) meestal om complexe problemen waarin institutionele en contractuele gegevens een belangrijke rol spelen. Daarmee is aandacht voor de verschillende 'imperfecties' een absolute noodzaak geworden en is de eerder aangehaalde uitspraak van Dufey en Srinivasulu (1983) te zien als een, overigens hoogst nuttig, vooral door didactische overwegingen bepaald vertrekpunt van behandeling van het thema 'financiële innovaties' in de leerboeken.

\section{Financieel beleid dus relevant?}

De analyse in de vorige paragraaf suggereert enige relevantie voor het financiële beleid. Hoewel in het voorgaande de nadruk lag op de invloed van fricties op de financiering van de onderneming zijn deze evenzeer van invloed op de risicomanagementproblematiek. In deze paragraaf laten we zien hoe door fricties in de financiële markten, of tussen onderneming en buitenstaanders, vele aspecten van het financieel beleid aan belang winnen. Achtereenvolgens bespreken wij een tweetal rationalisaties van hedging (risicomanagement), het belang van 'structured deals' in de financiering van ondernemingen, en het gebruik van afgeleide financiële instrumenten ter ondersteuning van het investeringsbeleid.

\section{Hedging en doorzichtigheid: Een kritische} determinant voor risicomanagement is de mate waarin hedging bijdraagt aan de doorzichtigheid (transparantie) van een onderneming. Voor de juiste gedachtebepaling merken wij op dat conglomeraatvorming gezien kan worden als een vorm van hedging (door middel van diversificatie). Echter conglomeraatvorming vermindert de doorzichtigheid van de onderneming. Dit leidt mogelijk tot een gebrek aan 'accountability' van het management, en evenzeer een verwaterde focus. Hiermee bedoelen we dat in een ondoorzichtige organisatie de efficiëntie van het management onder druk staat, en tevens moeilijk is te beoordelen waardoor het management mogelijk gevrijwaard is van het afleggen van verantwoording.

Hedging kan echter evenzeer de doorzichtigheid van een onderneming vergroten. Dit is ons inziens een belangrijke determinant voor risicomanagement. In het geval van valutarisico maakt het 
afdekken van bijvoorbeeld het risico van een fluctuerende dollar het resultaat voorspelbaarder, en mogelijk een betere afspiegeling van de kwaliteiten van het management. Dit is met name relevant als buitenstaanders het valutarisico van de onderneming maar moeilijk kunnen inschatten, terwijl dat voor de ondernemingsleiding zelf wel mogelijk is. In dit geval maakt het dollarrisico de onderneming minder doorzichtig en heeft het zonder te hedgen de mogelijkheid om - misschien ten onrechte - een tegenvallend resultaat te wijten aan valutaire tegenwind. Hiermee is het gerealiseerde resultaat van de onderneming voor beleggers minder informatief over de kwaliteiten van het management, en daarmee 'profiteert' het management mogelijk van het eerder genoemde gebrek aan accountability. Er is, met andere woorden, een zekere mate van ruis aanwezig in de beoordelingsmogelijkheden door de vermogensverschaffers en andere stakeholders. Het alternatief is dat de ondernemingsleiding de instructie heeft om valutarisico helemaal af te dekken of binnen een bepaalde bandbreedte te houden. Hiermee wordt de informatieve waarde van het te realiseren resultaat vergroot en daarmee de accountability. Het is belangrijk om in te zien dat beleggers door zelf te hedgen deze gewenste doorzichtigheid niet kunnen bewerkstelligen, zij zijn immers in het ongewisse over de mate waarin sprake is van valutarisico. Bovendien zijn er toegangsdrempels op de financiële markten. Juist dit laatste maakt risicomanagement op ondernemingsniveau van belang; bij volledige doorzichtigheid zouden beleggers namelijk mogelijk beter zelf risico's kunnen heralloceren (en afdekken) in de financiële markten, en is het onnodig dat dat gebeurt op ondernemingsniveau. ${ }^{2}$

\section{Hedging, voorspelbaarheid en faillisse-} mentskosten: Een ander argument voor hedging dat erg dicht tegen het belang van doorzichtigheid aanligt, is de onwenselijkheid van willekeurige schommelingen in kasstromen en winsten veroorzaakt door factoren die op generlei wijze beïnvloedbaar zijn door het management. De motivatie van het management (en het personeel) is ermee gediend als het resultaat van de onderneming een afspiegeling geeft van hun kwaliteiten en inspanningen; hedgen kan hiertoe bijdragen. En wat te zeggen over het beheersen van het faillissementsrisico, een toch niet te verwaarlozen factor. Valuta- en renterisico's mogen dan misschien een vooral exogeen karakter bezitten, de onderneming zou door (onverwachte) valuta- of renteschommelingen wel degelijk ten onder kunnen gaan. Hiertegen moet een onderneming zich inderdaad indekken. Dit zorgt er ook voor dat de kasstromen van de onderneming meer voorspelbaar worden waardoor de onderneming een veel geordender en voorspelbaarder beroep kan doen op externe financiering. Het hedgingbeleid speelt hiermee ook in op de toekomstige liquiditeitsbehoefte van de onderneming. Centraal hierbij staat wederom de doorzichtigheid van de onderneming. Het mag niet zo zijn dat ten behoeve van de voorspelbaarheid de doorzichtigheid wordt aangetast. Inefficiënties zijn dan ons deel.

\section{'Structured deals', afgeleide financiële instrumenten en financiering (funding): Finan-} ciële instrumenten in haar vele variaties kunnen evenzeer van pas komen bij het optimaliseren van de vermogensstructuur. Er kan bovendien een nauwe wisselwerking bestaan tussen afgeleide financiële instrumenten en directe financieringsinstrumenten waardoor de uiteindelijke financieringskosten lager uitvallen. Men kan hierbij denken aan snelheid en flexibiliteit. Zo kan een onderneming snel en tegen lage transactiekosten inspelen op marktbewegingen zonder de eigenlijke vermogensstructuur aan te passen. Bijvoorbeeld door gebruik van swaps, futures en opties kan de rentegevoeligheid van de passiva snel worden bijgesteld. Dit duidt op een groot flexibiliteitsvoordeel. Derivaten kunnen ook een direct voordeel hebben bij het aantrekken van financiering. Het kan bijvoorbeeld goedkoper zijn om voor het verkrijgen van financiering met vaste rente eerst een obligatielening met een variabele rente uit te geven en vervolgens door een swap de variabele rentelast om te zetten in een vaste renteverplichting. Zo zou het ook goedkoper kunnen zijn om als een variabele rente gewenst is, eerst te lenen tegen een vaste rente en daarna met een swap de rente effectief variabel te maken. Anderzijds is het ook mogelijk om een variabel rentend krediet in rekening-courant een vaste rente te bezorgen door middel van een swap.

Het is verre van voor de hand liggend waarom het lenen tegen een variabele rente met daar bovenop een swap goedkoper zou kunnen zijn dan het direct lenen tegen een vaste rente. Hetzelfde geldt voor de andere transacties. Een belangrijk 
punt is dat de vergoeding voor het faillissementsrisico op lang vreemd vermogen over het algemeen hoger is dan die op kort vreemd vermogen. Een verklaring is dat bij kort vreemd vermogen de vermogensverschaffer meer invloed kan uitoefenen op de onderneming. Zij kan dan immers eisen stellen aan de voortzetting van het krediet, en heeft de mogelijkheid om condities op de lening aan te passen. Hierdoor is de onderneming beter te beheersen door de vermogensverschaffer die dan ook een dienovereenkomstige lagere vergoeding zal eisen. Dit suggereert dat ondernemingen, door met kort vreemd vermogen te financieren, hun financieringskosten kunnen verlagen. Uiteraard heeft dit wel zijn prijs, de onderneming loopt een renterisico. Dit kan ongewenst zijn omdat het resultaat van de ondernemingsactiviteit daarmee wordt vertroebeld. Zoals wij hebben aangegeven is dit niet gewenst: het vermindert de doorzichtigheid en stelt de onderneming bloot aan een groter faillissementsrisico. Anderzijds kan het tot gevolg hebben dat het management afziet van bepaalde investeringsprojecten omdat de toekomstige financieringslasten te onvoorspelbaar zijn. Afgeleide instrumenten kunnen ook hier uitkomst bieden. Met een swap heeft de onderneming de mogelijkheid om voor een bepaalde periode haar variabele renteverplichting om te zetten in een vaste renteverplichting. Hiermee kan zij zich financieren met korte-termijnleningen en dus mogelijk profiteren van een lagere kostenvoet van vermogen zonder dat daarbij renterisico wordt gelopen. $^{3}$

Afgeleide financiële instrumenten en investeringsbeleid: Financiële instrumenten kunnen ook een nuttige bijdrage leveren aan de beheersing van investeringen die zullen gaan plaatsvinden of reeds hebben plaatsgevonden. Een treffend voorbeeld van het eerste type gebruik is de rol die valuta-opties kunnen spelen bij een buitenlandse overname van een onderneming waarbij een valutarisico aanwezig is. Zolang het bod niet is geaccepteerd, is er een contingent valutarisico dat om afdekking vraagt. KPN bracht bijvoorbeeld een bod uit op het Australische bedrijf TNT dat per procent wisselkoersverandering Australische dollar/gulden $f 27$ miljoen verschil in investering zou opleveren. Dit risico werd met opties afgedekt. Voorbeelden van het tweede type zijn de transacties die ten doel hebben om valutarisico in vorderingen op buitenlandse debiteuren, en prijsrisico's van grondstoffen af te dekken. In beide gevallen is de belangrijkste boodschap dat zonder afgeleide instrumenten grotere risico's worden gelopen waardoor mogelijk investeringen niet hadden plaatsgevonden.

\section{Slot}

Financiële instrumenten, zowel derivaten als allerlei opgetuigde, 'on the balance sheet' instrumenten, kunnen van grote waarde zijn voor ondernemingen. Voor sommigen is dit 'een open deur', voor velen echter vormen deze instrumenten een onbegrepen fenomeen. In deze bijdrage hebben wij laten zien dat het onbegrip over financiële instrumenten - en het financieel management in het algemeen - veel dieper gaat. De vraag is of het financiële beleid van de onderneming werkelijk waarde toevoegt of dat dit louter voorbehouden is aan de reële activiteit?

Ons antwoord is eenduidig. De vele imperfecties - zoals transactiekosten en informatieverschillen tussen onderneming en buitenwereld maken het financiële beleid van primaire betekenis. Financiële instrumenten, zowel op de balans als daarbuiten, zijn hierbij niet weg te denken schakels. Vooral de off-balance sheet instrumenten zorgen voor optimale flexibiliteit, en zijn onmisbaar voor een verantwoord risicomanagementbeleid. In de hierop volgende bijdragen in dit themanummer wordt de mystiek van het hoe en waarom van financiële innovaties verder ontrafeld.

\section{I T E R A T U U R}

Boot, A.W.A. en P. Verheyen, (1997), Financiering en macht: van financiële structuur tot beheersstructuur, Kluwer, Deventer, te verschijnen augustus 1997

Boot, A.W.A. en J. Ligterink, (1995), Derivaten: zinvolle toepassingen en het grote onbegrip, Economische Statistische Berichten, 80, pp. 292-295.

Dufey, Gunter, en S.L. Srinivasulu, (1983), The Case for Corporate Management of Foreign Exchange Risk, Financial Management, Winter 1983, pp. 54-62

Duffhues, P.J.W., (1997), Ondernemingsfinanciering en vermogensmarkten, deel 2, tweede druk, Wolters Noordhof, Groningen

Duffhues, P.J.W., (1994), Economische functies en verslagge- 
vingsaspecten van financiële instrumenten, in: C.M.T. Boneco, R.L. ter Hoeven, R.F. Speklé, R. van der Wal (red.), fMA Kroniek 1994, pp. 89-108.

Duffhues, P.J.W., (1997), Inovatieve 'index-linked' beleggingsinstrumenten, MAB, pp. 354-360.

Klaassen, A., (1997), Kader: Financiële risico's: een praktijkonderzoek. MAB, pp. 372-373.

Schoten, E.M.A. van, (1997), Control van financiële derivaten, een empirisch onderzoek in Nederland, MAB, pp. 374-382.

Smid, P.P.M. en F.M. Tempelaar, (1997), Belegging in 'click'fondsen, $M A B$, pp. 361-371.

Ven, P.L.M. van de, (1997), Macromarkten en het verzekeren tegen macro-economische risico's, MAB, pp. 344-353.

Bongartz-Renaud, D., (1993), 'Nieuwe generatie'-opties, in:
P.J.W. Duffhues, J. Groeneveld en J. van der Hilst (red.)

Financiële instrumenten (Moderne vormen van financiering en risicobeheersing), Kluwer, Deventer.

\section{N O T E N}

1 Zie voor nadere uitwerking Boot en Verheyen (1997) en Duffhues (1997).

2 Het belang van hedging is verder uitgewerkt in Boot en Ligterink (1995).

3 Merk op dat een swap een afzonderlijke financiële transactie is, die het bovenbeschreven beheersbaarheidsvoordeel van de korte financiering niet aantast. 